\title{
CRUELDAD Y VIOLENCIA EN LOS PERSONAJES FEMENINOS DE HERÓDOTO *
}

\begin{abstract}
En la Historia de Heródoto abundan las menciones a personajes femeninos. En contra de lo que pudiera pensarse, las mujeres no son presentadas de forma estereotipada, sino que son caracterizadas de manera compleja. Hay que destacar a las mujeres dotadas de poder, más proclives al empleo de la violencia, a menudo desmesurada, para lograr sus objetivos políticos o personales.

Palabras clave: Heródoto, política, mujeres, pensamiento etnográfico, violencia.
\end{abstract}

MANUEl AlbaladeJo VIVERO Universidad de Friburgo
In History, Herodotus mentions a great quantity of female characters. They are not presented, however, as stereotypes, they appear as complex characters. The most remarkable are those women that hold power, more inclined to violence, many times disproportionate, in order to achieve their political or personal ambitions.

Key words: Herodotus, politics, women, ethnographical thought, violence.

Para asombro de lectores antiguos y modernos, la Historia de Heródoto contiene un amplio número de referencias a mujeres, hasta el punto de tratarse de una de las obras que, en la Antigüedad clásica, las mencionó con mayor profusión ${ }^{1}$.

En su obra, las mujeres no sólo cumplen su función tradicional como amas de casa ${ }^{2}$ y madres de personajes relevantes, sino que también gozan de

* Este artículo fue redactado en el Seminar für alte Geschichte de la Albert-Ludwigs Universität de Friburgo (Alemania) aprovechando el disfrute de una beca postdoctoral en el extranjero concedida por la Secretaría de Estado de Universidades del Ministerio de Educación y Ciencia. Agradecemos sinceramente al Prof. Dr. Hans-Joachim Gehrke las sugerencias que han servido para mejorar nuestro trabajo.

En este sentido, sólo tenemos que recordar que los primeros capítulos del libro I se encuentran dedicados a los numerosos secuestros de mujeres protagonizados por griegos y bárbaros como antecedentes míticos del gran enfrentamiento entre griegos y persas a comienzos del siglo $\mathrm{V}$ a.C.

2 Acerca de esta cuestión, G. González Almenara, «Algunas consideraciones sobre el papel de las esposas en las Historias de Heródoto y Tucídides», en J.F. González Castro (ed.), Actas del IX Congreso Español de Estudios Clásicos, Vol. 6, Madrid, 1998, pp. 105-108, distinguió tres formas diferentes en que aparece representada la esposa: 1. Como vínculo de unión entre las familias de su padre y de su esposo. 2. Como elemento imprescindible para per- 
un papel activo dentro de sus respectivas culturas, apareciendo a menudo como contrapeso a la actuación pública o privada de sus esposos, buscando con ello obtener unas relaciones sociales equilibradas, siempre y cuando esto fuera posible dentro de la mentalidad helénica ${ }^{3}$.

En general, se puede afirmar que Heródoto no reflejó dentro de su obra un estereotipo femenino (teniendo en cuenta, por supuesto, los estrechos límites impuestos a las mujeres en la sociedad y en la mentalidad griegas), sino que dotó de una personalidad más o menos definida a muchas de las mujeres que transcurren por las páginas de su obra ${ }^{4}$. En realidad, esta escasez de estereotipos o de ideas preconcebidas ${ }^{5}$ se trata de una característica propia del método investigador del de Halicarnaso, que puede hallarse, por ejemplo, en sus numerosas descripciones etnográficas.

Las mujeres por él mencionadas pertenecieron a los más diversos estratos de la sociedad: reinas, princesas, concubinas, sacerdotisas, esposas fieles o prostitutas jalonan sus páginas dentro de unos relatos o logoi que contienen materiales de procedencia diversa: mitos, leyendas, relatos etiológicos, tradiciones orales mantenidas por diversas familias o simples habladurías, todos ellos conocidos por nuestro autor y, en numerosas ocasiones, reelaborados según sus intenciones narrativas.

Dentro de ese variado elenco de representantes del género femenino, destaca con luz propia un grupo de mujeres caracterizadas con una personalidad extremadamente cruel o vengativa, en consonancia con algunos personajes arquetípicos del mundo de la tragedia ateniense que él conoció de primera

petuar el oikos de su marido y 3. Como transmisora de la herencia de éste o de su padre a sus hijos.

Con esta afirmación no nos referimos a una supuesta "igualdad" entre hombres y mujeres, que no existió durante la Antigüedad, sino al mantenimiento de una serie de valores y de costumbres que garantizarían la identidad del grupo humano al que pertenecían. Véanse, además, las interesantes apreciaciones de J.H. Blok, "Women in Herodotus' Histories", en E.J. Bakker, I.J.F. de Jong y H. van Wees (eds.), Brill's Companion to Herodotus, Leiden, 2002, pp. 225-242, especialmente pp. 225 y 227.

4 C. Dewald, "Women and culture in Herodotus' Histories", en H.P. Foley, Reflections of Women in Antiquity, Nueva York, 198633 , pp. 91-92, quien asimismo señaló que Heródoto citó 375 veces a mujeres dentro de su obra. También es interesante consultar S. Pembroke, "Women in Charge: the function of Alternatives in Early Greek tradition and the ancient Idea of Matriarchy", Journal of the Warburg and Courtauld Institutes, 30, 1967, pp. 1-35; D. Lateiner, The Historical Method of Herodotus, Toronto, 1989, p. 136.

${ }_{5}$ Siempre en comparación con las mantenidas por sus contemporáneos e incluso con los autores griegos posteriores.

EMERITA (EM) LXXV 2, julio-diciembre 2007 pp. 299-317 ISSN 0013-6662 
mano ${ }^{6}$.

Curiosamente, muchos de los ejemplos que vamos a exponer en el presente trabajo son de mujeres de origen bárbaro que, además, se encuentran en una posición de preeminencia dentro de sus respectivas sociedades ${ }^{7} \cdot i$ Tiene algún significado la coincidencia de los tres elementos: feminidad, no pertenencia al mundo griego y poder político o se trata simplemente de eso, de una combinación al azar? En primer lugar, expondremos los personajes y, al final, intentaremos ofrecer una explicación a nuestra pregunta.

Podríamos empezar precisamente por la escala más alta de la sociedad: se nos dice que Nitocris ${ }^{8}$ fue la única mujer que reinó en Egipto de un total de 330 monarcas $^{9}$ y sucedió en el trono a un hermano suyo que había sido asesinado. Al llegar a este punto, no aclara el autor ni los móviles del crimen ni quiénes fueron los responsables del mismo; tan sólo habla de "los egipcios"

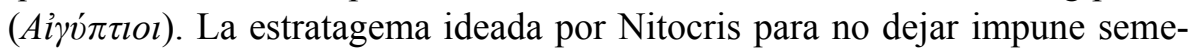
jante delito consistió en la construcción de una amplia cámara subterránea. A continuación invitó al banquete de inauguración que se celebró en la misma a aquellos egipcios que ella sabía eran responsables de la muerte de su hermano y sobre quienes arrojó el agua del Nilo canalizada a través de un gran conducto secreto.

Heródoto finalizó este breve relato sobre Nitocris señalando que sus informantes - es decir, algún sacerdote egipcio - le indicaron que, cumplida su

Algunos buenos ejemplos han sido recogidos por W.V. Harris, "The rage of women", en S. Braund y G.W. Most, Ancient Anger. Perspectives from Homer to Galen, Cambridge, 2003, pp. 131, 140-143.

Como señaló E. Hall, Inventing the Barbarian. Greek Self-Definition through Tragedy, Oxford, 1989, p. 95: "This may simply be because it was a 'law' of Greek ethnography that the more barbarian a community the more powerful its women".

8 Su nombre significa "Neith es excelente" y fue bastante habitual en la Época Tardía. Por otro lado, en el Canon de Turín aparece cierta Nitokerti reinando a finales de la 6 a dinastía, mientras que Manetón mencionó en su lista una Nitocris en esa misma época, quien mandó construir la tercera pirámide (el sacerdote egipcio confundió la tradición referente a Nitocris con la leyenda de la cortesana Rodopis, que se contiene en Hdt. II, 134-135). A. Gardiner, Egypt of the Pharaohs. An Introduction, Oxford, 1961, p. 102; A.B. Lloyd, Herodotus. Book II. Commentary 99-182, Leiden, 1988, pp. 13-15 y Erodoto, Le Storie, Libro 2, Introduzione, testo e commento, Milán, $1993^{2}$, p. 323.

9 Hdt. II, 100. La cifra puede referirse al total de reyes egipcios existentes entre Min y

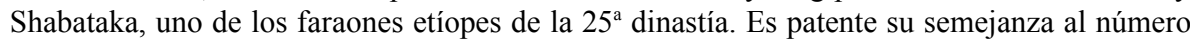
de 329 soberanos que ofreció Manetón para el mismo período. A.B. Lloyd, "Herodotus Account of Pharaonic History", Historia, 37, 1988, pp. 33-38.

EMERITA (EM) LXXV 2, julio-diciembre 2007 pp. 299-317 ISSN 0013-6662 
venganza, la reina se arrojó a un habitáculo lleno de brasas para evitar las represalias sobre su persona.

Independientemente de los aspectos folclóricos presentes en la narración como el tema de la fête fatale ${ }^{10}$ - de un texto que tuvo bastante fama en la Antigüedad ${ }^{11}$, no pasa desapercibido el papel que juega la actividad hidráulica en el contexto del relato. La Nitocris egipcia, al igual que su homónima babilónica ${ }^{12}$, lleva a cabo una considerable obra pública relacionada, en primer lugar, con una excavación que luego es colmada de agua.

Al mismo tiempo, existe una contradicción entre ambas actuaciones: si en Babilonia la construcción del lago artificial reporta un beneficio a todos los habitantes de la ciudad, que se encuentran mejor protegidos ante una posible invasión de los medos; en Egipto, la obra responde a una venganza premeditada de carácter, por supuesto, personal. En definitiva, nos encontramos ante un buen ejemplo del quehacer literario de Heródoto, al poner en escena dos pasajes bastante alejados y en contextos diferenciados que, en principio, presentan ciertos paralelismos, pero que tienen unas consecuencias radicalmente diferentes.

El tema de la venganza se encuentra asimismo presente en el retrato de Tomiris ${ }^{13}$, la soberana de los maságetas, un pueblo bárbaro que habitaba las llanuras el este y nordeste del mar Caspio, a la que Ciro quiso desposar para apropiarse de su reino ${ }^{14}$. La personalidad de esta mujer es rápidamente esbo-

10 A.B. Lloyd, Herodotus. Book II. Introduction, Leiden, 1975, p. 107 y "Herodotus' Account", pp. 39-40.

Hubo varias versiones posteriores de la leyenda de Nitocris, como la de Manetón, F.Gr.Hist. 609 F 2, F 3 a y F 3 b; Eratóstenes, F.Gr.Hist. 610 F $1<\mathrm{kb}>$; Cass. Dio LXII, 6 y Iul., Orationes III, 129 b.

12 A quien Hdt. I, 185-187, atribuyó numerosas obras hidráulicas y defensivas puestas en marcha realmente por Nabucodonosor II, acaso el más importante monarca neobabilónico. Según nuestro autor, la intención de esta reina fue la de impedir un ataque medo desde el Norte abriendo numerosos canales en el Éufrates y variando su curso, lo que produjo la creación de numerosos meandros. En su relato, Heródoto destacó la que consideraba la mayor obra de esta Nitocris: la realización de un enorme lago artificial en disposición paralela al río. H.R. Immerwahr, Form and Thought in Herodotus, Cleveland, 1966, p. 26; A. Tourraix, "La femme et le pouvoir chez Hérodote", DHA, 2, 1976, p. 376.

13 Hdt. I, 205-214.

14 K.M.T. Atkinson, "The legitimacy of Cambyses and Darius as kings of Egypt", JAOS, 76,1956 , p. 175. Hay que observar que esta reina, al igual que hizo la Nitocris babilónica, se mantuvo decidida a preservar la integridad de sus posesiones haciendo frente a cualquier amenaza exterior.

EMERITA (EM) LXXV 2, julio-diciembre 2007 pp. 299-317 ISSN 0013-6662 
zada por Heródoto a través del mensaje que le hizo llegar a Ciro cuando éste se dispuso a atacar a los maságetas ${ }^{15}$. Tomiris es presentada como una reina valerosa que se permite aconsejarle al "Gran Rey" que abandone sus proyectos bélicos ${ }^{16} \mathrm{y}$ que se dedique a gobernar a sus súbditos; como era consciente de que Ciro iba a seguir adelante con sus planes, ella se presentó dispuesta a combatir, tanto en su país como en la propia Persia.

Acto seguido, Ciro convocó una reunión de los persas principales y decidió seguir el consejo de Creso para invadir el país de los maságetas, lo cual incluía una estratagema consistente en dejar en el campamento las peores tropas preparando un banquete que incluía grandes cantidades de vino puro como bebida ${ }^{17}$. Por supuesto, Creso pensaba que los bárbaros maságetas desconocían este lujo, un producto consumido por las sociedades más sofisticadas del momento ${ }^{18}$.

La estratagema de Creso resultó ser todo un éxito: los maságetas se hartaron de comer y beber después de asaltar fácilmente el campamento persa y el grueso de las tropas de Ciro acabó con muchos de ellos y apresó a los demás ${ }^{19}$. Entre estos últimos se encontraba Espargapises ${ }^{20}$, el hijo de Tomiris, quien se suicidó cuando se encontró sobrio y comprendió lo que había suce-

15 Hdt. I, 206. En opinión de C. Dewald, "Women and culture", p. 109, se trata de una "noble salvaje" que dirige la campaña militar de una forma "homéricamente irreprochable".

16 La moderación que Tomiris muestra al principio del relato se convierte en una cruel venganza al final del mismo. A. Tourraix, "La femme et le pouvoir", p. 377. Por otra parte, otra reina-guerrera que goza de cierto protagonismo -e incluso de la simpatía de Heródoto en VII, 99- durante la batalla de Salamina, Artemisia de Halicarnaso, no presenta ninguna característica vengativa o cruel; al tratarse de una reina vasalla de Jerjes, lucha a favor de los persas mostrando un coraje "masculino" - ajndrhivh-, en contraposición a los persas y fenicios que huyeron de la batalla. Hdt. VII, 99; VIII, 68, 87-88. J.S. Romm, Herodotus, Yale, 1998, pp. 171-172.

17 El mismo ardid fue citado, aunque con algunas variantes, por Iust. I, 8. Véase el interesante comentario al respecto de J.S. Romm, Herodotus, pp. 107-108.

18 Hdt. I, 207 y 216. Al tratarse de un pueblo nómada de las estepas, su bebida natural era la leche obtenida de sus rebaños, al igual que les ocurría a los escitas, los pioneros en el consumo del vino sin mezclar.

19 M. Rosellini y S. Saïd, "Usages de femmes et autres nomoi chez les 'sauvages' d'Hérodote: essai de lecture structurale", $A S N P$ serie III, 8, 1978, p. 968, señalan que Ciro repitió en esta ocasión la misma estratagema que Odiseo había empleado contra Polifemo.

20 Dicho nombre debía de ser bastante común entre la realeza de los pueblos iranios y escitas, ya que en Hdt. IV, 76 y IV, 78 son mencionados sendos Espargapites, el primero de ellos fue un rey escita, bisabuelo del sabio Anacarsis, mientras que el segundo lo fue de los agatirsos, un pueblo vecino de los escitas. 
dido.

El siguiente mensaje de Tomiris a Ciro, emitido cuando su hijo aún no había acabado con su vida, fue mucho más contundente que el primero ${ }^{21}$ : los persas se habían valido de un truco burdo para vencer a los suyos evitando un combate directo (propio, por tanto, de los pueblos primitivos, pero no por eso menos valerosos); no obstante, ella le concedía una segunda oportunidad en caso de que el "Gran Rey" le devolviese a su hijo, en caso negativo, le prometía saciarlo de sangre.

Al volverse imposible el cumplimiento de esta condición y puesto que Ciro no se retiraba a Persia, la batalla resultó inevitable. Según Heródoto, se trató de la más reñida de todas cuantas hubo entre bárbaros ${ }^{22}$ y culminó con el aniquilamiento del ejército persa y con la muerte del propio Ciro.

En cumplimiento de su promesa, Tomiris llenó de sangre humana un odre e introdujo en el mismo la cabeza de su enemigo ${ }^{23}$, llevando a cabo de esta manera una contrapartida irónica a la "invitación" realizada por Ciro a los maságetas a beber vino ${ }^{24}$.

Otra reina, en este caso, consorte, que juega un importante papel al co-

21 Se recoge en Hdt. I, 212 y, al igual que ocurrió con la anterior misiva, fue totalmente inventado por Heródoto.

22 La misma contienda fue asimismo mencionada por Frontin., Str. II, 5, 5 y por Polyain. VIII, 28.

${ }^{23}$ Hdt. I, 214. El autor indicó que, de entre todas las versiones de la muerte de Ciro, ésta le parecía la más probable. En cambio, Ctesias de Cnido recogió otra muy diferente en F.Gr.Hist. 688 F 6; concretamente, escribió que el fundador del Imperio Aqueménida pereció como consecuencia de una herida recibida en la campaña contra los derbices. Por su parte, el Ciro de Jenofonte en Cyr. VIII, 7, falleció en la cama rodeado de sus familiares y amigos. En fin, unas décadas después, Onesícrito de Astipalea señaló en F.Gr.Hist. 134 F 36 que el motivo de su muerte fue la tristeza, después de haber comprobado a los cien años de edad que todos sus amigos habían sucumbido a manos de su hijo Cambises, quien, por su parte, se defendía afirmando que se había limitado a cumplir sus órdenes. Por último, Diod. Sic. II, 44, 2, recogió una variante de la tradición seguida por Heródoto según la cual Ciro habría sido crucificado por una reina de los escitas.

24 Este tipo de "contrapartida trágica" es un castigo muy característico dentro del mito griego y Heródoto lo aplicó con profusión dentro de su narrativa como, por ejemplo, en IV, 2, con los esclavos cegados por los escitas. A. Griffiths, "Kissing Cousins: Some Curious Cases of Adjacent Material in Herodotus", en N. Luraghi (ed.), The Historian's Craft in the Age of Herodotus, Oxford, 2001, pp. 168-173. A propósito de Ciro y Tomiris véanse asimismo los comentarios de H.R. Immerwahr, Form and Thought, pp. 166-167 y de M. Rosellini y S. Saïd, "Usages de femmes", p. 969. 
mienzo de la Historia es la esposa de Candaules ${ }^{25}$, cuyo nombre desconoce$\operatorname{mos}^{26}$. Su extraordinaria belleza y el orgullo que por ello siente su marido se convertirán precisamente en las causas de su desgracia. Recordemos que Candaules quiere mostrársela desnuda a Giges, su hombre de confianza y, para conseguir su objetivo, decide ocultar a su ayudante dentro de su dormitorio. Giges logra cumplir el deseo de Candaules pero, al mismo tiempo, es descubierto por la mujer, quien, más astuta que su esposo, se las ingenia para cambiar la correlación de fuerzas colocando a Giges en la coyuntura de asesinar a Candaules y casarse con ella o, por el contrario, de ser él mismo ejecutado. Dentro de este "cuento oriental" adaptado por Heródoto casi con toda seguridad y aderezado con un toque de erotismo prohibido y de violencia $^{27}$, resulta fundamental el nomos bárbaro alrededor del cual se desata la tragedia: las mujeres que no eran griegas manifestaban un gran pudor para mostrar su desnudez ${ }^{28}$, una acción que consideraban un insulto a su digni$\operatorname{dad}^{29}$; por tanto, la reina tendrá que recurrir a una medida extrema para lim-

25 Hdt. I, 8-12. Sobre la enorme producción científica acerca del logos lidio en general y de este cuento en particular, C. Talamo, "Erodoto e le tradizioni sul regno di Lidia", Storia della Storiografia, 7, 1985, pp. 150-163. Además, es interesante consultar los análisis de A. Heuss, "Motive von Herodots lydischem Logos", Gesammelte Schriften in 3 Bänden I, Stuttgart, 1995, pp. 68-102 (= Hermes, 101, 1973, pp. 385-419) y de E. Wolff, "Das Weib des Masistes", Hermes, 92, 1964, pp. 51-81, quien puso de manifiesto que Heródoto enmarcó su gran tema de investigación (el conflicto entre Grecia y Persia) entre dos historias paralelas: la de Giges y la de los amores de Jerjes con su cuñada y su sobrina.

26 Incluso la verdadera onomástica del rey destronado por Giges era Mirsilo, no Candaules, que era el nombre de una divinidad meonia a la que se sacrificaban perros y que los griegos tendieron a identificar con Hermes o Heracles. J.G. Pedley, "Carians in Sardis", JHS, 94, 1974, pp. 96-99. Por otro lado, en las demás fuentes que tratan esta historia, el nombre de la reina varía desde Nisia y Clitia hasta Abro y Toudo. Véase, por ejemplo, Nicolás de Damasco, F.Gr.Hist. 90 F 47.

27 W. Aly, Volksmärchen, Sage und Novelle bei Herodot und seinen Zeitgenossen, Gotinga, $1969^{2}$, pp. 34, 224, 246-248. Por otro lado, como bien señaló J.S. Romm, Herodotus, p. 120 , este relato proporciona dentro de la obra de Heródoto un importante precedente a la catastrófica caída de Creso. Un análisis diferente, pero con algunas ideas interesantes es el de A. Tourraix, "La femme et le pouvoir", pp. 369-371.

28 G. Burzacchini, "Nudità e vergogna presso lidi e barbari: (Hdt. I, 10, 3), Eikasmos, 12, 2001, pp. 85-88.

${ }_{29}$ De todas maneras, en Grecia era relativamente frecuente observar jóvenes varones desnudos en las competiciones deportivas y en los coros. La desnudez femenina era menos habitual y, por supuesto, afrentar a una mujer como ocurre en el pasaje de Heródoto no era concebible en ninguna polis. Además, en Hdt. I, 94, se dice que los lidios tenían la costumbre de obligar a prostituirse a sus propias hijas. 
piar su honor, injustamente mancillado por la caprichosa actuación de su marido.

Asimismo, la actuación de la mujer de Candaules (ahora de Giges) provocará en Lidia el cambio ${ }^{30}$ de la dinastía de los Heráclidas a los Mérmnadas, la cual será interrumpida tras la derrota de Creso, el primer bárbaro que sometió a algunas ciudades griegas, ante Ciro, quien dejó al poderosísimo Imperio Aqueménida ad portas.

El relato anterior ha sido vinculado por algún autor moderno ${ }^{31}$ con otro muy significativo que aparece, curiosamente, casi al final de la obra de nuestro autor: se trata de la venganza llevada a cabo por Amestris, la esposa de Jerjes contra la joven amante de este último, llamada Artaínta ${ }^{32}$.

En realidad, el "Gran Rey", después de haber sido vencido en Grecia, se dedicó en Sardes a las "intrigas de harén" enamorándose perdidamente de la mujer de su hermano Masistes, la cual nunca es mencionada por su nombre. En vista de que, a pesar de su insistencia, no conseguía el amor de su cuñada, Jerjes decidió que su hijo Darío desposase a Artaínta, la hija de Masistes, pensando que así le resultaría más sencillo acceder a sus pretensiones ${ }^{33}$. Después de celebrarse ese matrimonio pactado, Jerjes regresó a Susa, donde se olvidó de la mujer de Masistes, poniendo todo su interés en Artaínta, quien sí accedió a sus requerimientos.

A su vez, Amestris descubrió la infidelidad de su marido después de haberle regalado un vistoso manto con el que Jerjes fue a visitar a su amante. Como el soberano quedó complacido con ella, se comprometió a regalarle aquello que le pidiera y, Artaínta, jugando a favor del destino que se cernía sobre su familia, le pidió precisamente el manto.

Jerjes se resistió en un primer momento a entregárselo, consciente de que

\footnotetext{
30 D. Lateiner, The Historical Method of Herodotus, p. 141. El POxy 2382 contiene el llamado "Drama de Giges", una versión semejante a la del episodio que estamos comentando, aunque su datación continúa siendo objeto de debate. J.A.S. Evans, "Herodotus and the Gyges Drama", Athenaeum, 33, 1955, pp. 333-336; J.A.S. Evans, "Candaules, whom the Greeks name Myrsilus...", GRBS, 26, 1985, pp. 229-233; L. Belloni, "Il silenzio della basivleia: (POxy 2382 = TrGF II 664; Hdt. I 10-11)", Paplup, 9, 2000, pp. 101-110.

31 En concreto, por E. Wolff, "Das Weib des Masistes", pp. 51-58.

32 Recogido en Hdt. IX, 108-113 y formando una unidad cerrada dentro de este último libro de la Historia.

33 En realidad, no sabemos cómo tenían que funcionar las maquinaciones de Jerjes, puesto que la narración herodotea se muestra en este punto sumamente oscura.
} 
Amestris lo descubriría, pero, al haber realizado un juramento, no tuvo más remedio que acceder a la petición de su amante. Como cabría esperar, la esposa de Jerjes supo al poco que Artaínta llevaba el manto pero, de manera extraña dentro de la lógica interna del relato, en vez de concebir una venganza contra la joven, dirigió su rencor a su madre, pensando que había sido la instigadora del asunto.

El escenario elegido para dar rienda suelta a sus planes fue el del banquete ofrecido por el "Gran Rey" para celebrar su cumpleaños ${ }^{34}$, con ocasión del cual se distribuían regalos a los persas más destacados. Por supuesto, el regalo solicitado por Amestris consistió en la mujer de Masistes; al igual que había sucedido en la ocasión anterior, Jerjes mostró su oposición, pero, asimismo, acabó aceptando pesaroso la petición de su esposa, ya que tenía que atenerse a dicha costumbre.

Temiendo la venganza de Amestris, convocó en un aparte a su hermano Masistes para solicitarle que renunciase a su esposa y se casase en su lugar con una hija suya. Masistes rechazó los planes de Jerjes y se marchó airado de la sala. Mientras tanto, Amestris comenzaba a llevar a cabo su venganza en la persona de la mujer de Masistes mutilando sus pechos -que luego mandó arrojar a los perros-, su nariz, orejas, labios y lengua ${ }^{35}$; a continuación, la mandó a su casa, donde la contempló Masistes, quien tramó un complot que consistió en dirigirse a Bactria, su satrapía, en compañía de sus hijos y de algunos partidarios para sublevar la provincia contra Jerjes.

Éste, avisado de los planes de su hermano, envió tropas para asesinarlo durante el camino junto con sus hijos y quienes lo apoyaban, sin que sepamos más sobre la suerte de la esposa de Masistes ni siquiera si Artaínta se encontraba entre los sublevados.

En realidad, la crueldad de Amestris había aparecido en un pasaje anterior $^{36}$, con ocasión de una noticia que había escuchado Heródoto sobre ella y que consistía en que, durante su vejez, la esposa de Jerjes ordenó enterrar vivos a siete parejas de muchachos persas pertenecientes a distinguidas familias a modo de agradecimiento a la divinidad subterránea ${ }^{37}$ por su larga vida.

\footnotetext{
34 Acerca de la costumbre persa de celebrar el cumpleaños, Hdt. I, 133.

35 Es bien conocido que la mutilación se trataba de un castigo típicamente persa, especialmente aplicado a los traidores. Basta con recordar Hdt. III, 69, 118 y 154, además de Xen., Cyr. I, 9, 13.

36 En Hdt. VII, 114. W. Aly, Volksmärchen, Sage und Novelle, pp. 201-202.

37 Seguramente Ahrimán.
} 
En este pasaje ya indicaba nuestro autor la característica fundamental que iba a otorgar a la personalidad literaria de Amestris. No podemos afirmar con rotundidad que el sacrificio humano fuese una costumbre relativamente habitual entre los persas ${ }^{38}$, pero, de lo que no caber dudar es que espantaba a los griegos cuando unos inocentes eran sacrificados. Asimismo, el castigo infligido a la mujer de Masistes era excesivo y además injustificable, puesto que ella tan sólo había sido el objeto de deseo de Jerjes, quien al final cometió el adulterio con Artaínta, sin que sepamos nada acerca del posible papel jugado por ella dentro de esta relación extramatrimonial.

Por otro lado, se puede admitir que existen ciertos paralelismos entre la historia de la mujer de Candaules y la de Amestris ${ }^{39}$, aunque parece más claro que Heródoto nos presentó en esta ocasión a un Jerjes de personalidad voluble $^{40}$, encaprichado primero de su cuñada y, a continuación, de su sobrina y nuera, todo ello, una vez más, dentro de un ambiente típicamente "oriental", con sus intrigas de harén, entreveradas con los amores prohibidos e incluso una reacción sádica ${ }^{41}$. La venganza ideada por ambas mujeres es, además, de distinta intensidad, puesto que la de Candaules plantea la disyuntiva de o bien acabar con la vida del hombre que la ha contemplado ilícitamente, o bien asesinar a quien la ha mostrado desnuda. En cambio, Amestris no busca en ningún momento matar a Jerjes, el verdadero culpable de la relación extramatrimonial, sino que busca vengarse en la persona de la madre de la amante, de una forma un tanto incomprensible si pensamos que su intención es la de vengar la infidelidad de su esposo. En caso de que admitiésemos que el relato herodoteo consiste en la versión final -muy deformada a través de la tradición oral y de las inevitables adaptaciones realizadas por nuestro autor para divulgarla por el mundo griego- de la narración de la rebelión protagonizada por el hermano de Jerjes a la que se superpuso el tema

\footnotetext{
38 Aunque conocemos algún otro caso, por ejemplo, el de los doce persas de alta alcurnia enterrados vivos y cabeza abajo por orden de Cambises en Hdt. III, 35.

39 Ambas eran reinas consortes y habían sido traicionadas por sus respectivos maridos. De todas maneras, en el caso de la mujer de Candaules, no se había producido ninguna infidelidad, ya que el marido tan sólo la había expuesto desnuda a la mirada de un extraño, si bien para las mujeres "bárbaras" dicho acto consistía en un grave ultraje.

40 Sobre esta cuestión, W. Marg, "Herodot über die Folgen von Salamis", Hermes, 81, 1953, pp. 196-210.

${ }_{41}$ Como puso de manifiesto K.H. Waters, Herodotos on Tyrants and Despots. A Study in Objectivity, Wiesbaden, 1971, p. 84, quien, por lo demás, no aceptó la argumentación de E. Wolff.
}

EMERITA (EM) LXXV 2, julio-diciembre 2007 pp. 299-317 ISSN 0013-6662 
de los amores ilícitos del "Gran Rey", la venganza de Amestris sobre la mujer de Masistes adquiere un mayor significado ${ }^{42}$.

Otra mujer perteneciente a la realeza cuya actuación personal, según nuestro autor, produjo importantes consecuencias históricas fue Atosa, hija de Ciro el Grande, hermana y esposa de Cambises, a la muerte de éste, esposa del "falso Esmerdis" y, por último, de Darío ${ }^{43}$.

A los comentaristas de la obra herodotea no ha dejado de sorprenderles el interés que el de Halicarnaso mostró por diversas cuestiones relacionadas con el mundo natural y la medicina; en este sentido, Heródoto dejó testimonio del tumor de mama que afectó a Atosa y que fue convenientemente tratado por el especialista Democedes de Crotona ${ }^{44}$.

A cambio de su curación, Democedes le pidió que hablara en su favor a Darío para que él pudiese regresar a su ciudad y Atosa, mientras estaba acostada con el "Gran Rey" ${ }^{45}$, supo convencerlo astutamente (apelando incluso a

42 Ésta es la tesis de H. Sancisi-Weerdenburg, "Exit Atossa: Images of Women in Greek Historiography on Persia", en A. Cameron y A. Kuhrt (eds.), Images of Women in Antiquity, Londres-Canberra, 1983, pp. 28-30, quien afirmó que el relato se originó dentro de la tradición oral persa y que el tema de vestir la prenda del rey resulta crucial para entenderlo. Para los persas, se trataba de un tabú porque quien llevaba las ropas del soberano, asumía en realidad la realeza. Artaínta no la habría querido para sí, sino para su padre, que al final de la historia es asesinado. En definitiva, bajo la superficie de un cuento oriental, podría esconderse el recuerdo de un intento de rebelión por parte del hermano del "Gran Rey".

43 Tanto Atosa, como Feretima de Cirene, que será tratada más adelante, son claros ejemplos de mujeres dotadas de poder por haberlo heredado de sus respectivos padres. C. Dewald, "Women and culture", p. 115 n.8.

44 R. Thomas, Herodotus in Context. Ethnography, Science and the Art of Persuasion, Cambridge, 2000, p. 41. Sea verdadera o no la historia acerca del tumor, lo cierto es que Atosa vivió muchos años y tuvo hijos con Darío; es posible que se tratase de un tumor benigno. La interpretación de A. Tourraix, "La femme et le pouvoir", p. 379, en el sentido de que, al verse afectada la reina por un tumor, la fertilidad y la prosperidad del imperio también se encuentran en peligro, no nos parece demasiado pertinente.

45 No es necesario señalar -siempre irónicamente- que la fuente empleada por el autor para redactar este pasaje presenta graves problemas de identificación. Por supuesto, Heródoto no esperaba que su audiencia considerase verídica esta escena. H. Sancisi-Weerdenburg, "Exit Atossa" p. 25, se preguntó si la fuente de información acerca de este relato pudo haber sido la propia familia de Democedes, a cuyos descendientes habría conocido Heródoto en la Magna Grecia; en cuanto a la accesibilidad que tendría un médico griego a la familia real persa, es bien sabido que Ctesias de Cnido basó sus Persiká en informaciones recabadas en ambientes palaciegos.

EMERITA (EM) LXXV 2, julio-diciembre 2007 pp. 299-317 ISSN 0013-6662 
su virilidad ${ }^{46}$ ) para que enviase por vez primera una misión exploratoria a Grecia con el caprichoso pretexto de que ella quería tener esclavas griegas.

Este relato, nuevamente novelesco e insertado dentro del "cuento" del médico Democedes ${ }^{47}$, habla de la posición e influencia de que gozaba Atosa en la corte aqueménida, hasta el punto de que en la Historia es la persona que dio origen, en último término, a las Guerras Médicas. La naturaleza etiológica de este pasaje resulta del todo clara: de las primeras palabras que le dirige Atosa a Darío ${ }^{48}$ se desprende una reflexión política acerca de las actividades emprendidas por el gobernante y por su pueblo que un siglo más tarde sería retomada por Aristóteles ${ }^{49}$.

De entre todas las reinas sobre las que escribió Heródoto fue seguramente Feretima la retratada con una personalidad donde la crueldad e incluso la brutalidad se presentaron de una manera patente; por supuesto, el autor dejó claro que su caracterización psicológica estaba estrechamente vinculada a una masculinidad por supuesto impropia y ajena a la naturaleza femenina. Esta mujer, en concreto, había sido la esposa de Bato III de Cirene, apodado "el cojo" y el hijo de ambos fue Arcesilao III, quien reinó en dicha ciudad africana aproximadamente entre los años 530 y 510 a.C ${ }^{50}$.

Debido a que Arcesilao se negó a aceptar las normas que había estableci-

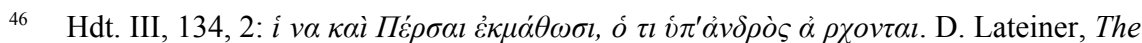
Historical Method, p. 139, destacó el carácter irónico que encierra esta afirmación. Una

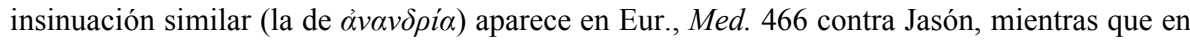
Aesch., Cho. 304, se dice que el alma de Egisto es "femenina" ( $\theta \dot{\eta} \lambda \varepsilon l \alpha \gamma \grave{\alpha} \rho \varphi \rho \dot{v} v)$.

Acerca del conocimiento de la obra de Heródoto por Eurípides, E. Hall, Inventing the Barbarian, p. 134 y, más general, sobre la relación entre nuestro autor y la tragedia, S. Saïd, "Herodotus and Tragedy", en E.J. Bakker, I.J.F de Jong y H. van Wees (eds.), Brill's Companion to Herodotus, pp. 117-147. Aunque, en realidad, lo más apropiado sería pensar en un conjunto de ideas comunes al pensamiento de la época que serían empleadas indistintamente por los diversos intelectuales.

47 Que abarca Hdt. III, 129-138 y contiene unos elementos absolutamente "orientalizantes", como las escenas dentro del palacio y del harén.

48 Hdt. III, 134: "ळ’ $\beta \alpha \sigma i \lambda \varepsilon \tilde{v} .$. . ". B. Shimron, "Politics and Belief in Herodotus", Historia Einzelschriften, 58, Stuttgart, 1989, pp. 6, 20, 53, 65. J.A.S. Evans, Herodotus, Explorer of the Past, Princeton, 1991, pp. 58-60.

49 En Pol. 1313 b 28, un pueblo que permanece ocioso supone un peligro latente para su soberano. K.H. Waters, "The Purpose of Dramatisation in Herodotos", Historia, 15, 1966, pp. 162-164.

50 B.M. Mitchell, "Note on the Chronology of the reign of Arkesilas III", JHS, 94, 1974, pp. 174-177.

EMERITA (EM) LXXV 2, julio-diciembre 2007 pp. 299-317 ISSN 0013-6662 
do en Cirene el legislador Demonacte ${ }^{51}$ de Mantinea, organizó una sublevación que no tuvo ningún éxito y, por ello, el propio Arcesilao y Feretima no tuvieron más remedio que partir para el exilio: él a Samos y su madre a Salamina de Chipre $^{52}$

Esta última ciudad se hallaba gobernada por el tirano Eveltón, a quien Feretima le solicitó con insistencia que prestase tropas para regresar por la fuerza a Cirene. Eveltón, por su parte, intentaba complacerla enviándole numerosos regalos que ella aceptaba pero añadiendo que sería más hermoso que le entregase un ejército. Por último, Eveltón la obsequió con un huso de oro y una rueca, diciendo que esos eran unos regalos apropiados para una mujer y no un ejército.

Resulta claro que la fuente empleada por Heródoto no sólo para narrar esta anécdota, sino también en todo el relato sobre Arcesilao y Feretima era hostil hacia ellos; el recuerdo dejado por ambos habría resultado tan negativo que todavía Heródoto pudo escuchar a los cireneos tales habladurías.

Continuando con su narración de los hechos, nuestro autor da a entender que Arcesilao volvió a hacerse con el control de Cirene gracias a las tropas que reclutó en Samos bajo la promesa de una entrega de tierras.

En cuanto a los prisioneros que hizo, se narra que los envió a Chipre (indudablemente para que su "adorable" madre se encargase de ellos), aunque por fortuna, los barcos que los transportaban perdieron la ruta y arribaron a Cnido, desde donde fueron expedidos a Tera ${ }^{53}$. Arcesilao, para evitar el cumplimiento de un oráculo de Delfos ${ }^{54}$, evitó entrar en Cirene y se dirigió a Barca, cuyo rey era su suegro, dejando como regente a Feretima ${ }^{55}$, una vez

51 Las reformas fueron enumeradas en Hdt. I, 161, donde se dice que Demonacte fue llamado a instancias de un oráculo emitido en Delfos. Dichos cambios fueron, a tenor de lo señalado por el texto, de carácter democrático, limitando considerablemente el poder real e incluyeron la organización de la población de Cirene en tres tribus. P. Chamoux, Cyrène sous la monarchie des Battiades, París, 1953, pp. 138-142.

52 Hdt. IV, 162. Es muy posible que ambas ciudades hubiesen tenido una importante relación con Cirene y por eso las eligieron Arcesilao y Feretima; además, el hecho de que los dos no se hubiesen exiliado en la misma ciudad indica un intento de alianza militar con ambas.

53 Hdt. IV, 164. Cnido era, al igual que Tera, una colonia espartana y ambas mantenían relaciones de "consanguinidad". A. Corcella, Erodoto, Le Storie, Libro IV, Milán, 1993, p. 355.

54 Recogido en IV, 163.

55 En IV, 165, se dice que ella se encargaba de dirigir los asuntos de la polis y

EMERITA (EM) LXXV 2, julio-diciembre 2007 pp. 299-317 ISSN 0013-6662 
hubo regresado de Chipre.

Arcesilao terminó siendo asesinado en Barca y Feretima volvió a exiliarse, esta vez en Egipto, ya controlado por Cambises. Los persas pusieron a disposición de Feretima todas las tropas con que contaban en el país del Nilo $^{56}$. Una vez que entraron en la ciudad de Barca, entregaron a la reina a aquellos implicados en el asesinato de Arcesilao ${ }^{57}$. Feretima los hizo empalar alrededor de la muralla ${ }^{58}$, mientras que hizo cortar los pechos a sus mujeres ${ }^{59}$ para colocarlos igualmente en torno al muro, un castigo considerado desde el punto de vista griego "bárbaro" y brutal.

Finalmente, Heródoto achacó el motivo de la penosa muerte de Fereti$\mathrm{ma}^{60}$ a la venganza divina, ya que, según advirtió, las venganzas demasiado crueles de los hombres resultan odiosas a los dioses ${ }^{61}$.

Las amazonas que aparecen mencionadas en la Historia también presentan ciertos rasgos de crueldad, si bien ésa no fue la principal característica con que las reflejó el de Halicarnaso.

En realidad, la presencia de las amazonas dentro de su obra responde al hecho de que él las convirtió en las antepasadas míticas de los belicosos saurómatas de su época ${ }^{62}$. Para dar fe de ello, se remontó a la contienda que

participaba en las sesiones del consejo.

56 Hdt. IV, 167.

57 Hdt. IV, 202.

58 Se trata de otro castigo típicamente persa, como señaló A. Corcella, Erodoto, Le Storie, Libro IV, p. 388.

59 El mismo castigo con el que comenzó Amestris el suplicio de la esposa de Masistes. Nos resulta imposible averiguar si Feretima lo aplicó sabiendo que era una pena inequívocamente persa o si se trata de una macabra coincidencia.

${ }_{60} \mathrm{Su}$ cuerpo se vio invadido por gusanos. Hdt. IV, 205.

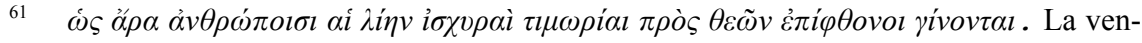
ganza divina frente a los excesos cometidos por los hombres es una constante moral dentro de la obra de Heródoto. H.R. Immerwahr, Form and Thought, p. 313; W.V. Harris, "The rage of women", p. 132. Por su parte, W. Aly, Volksmärchen, p. 135, comparó la horrible muerte padecida por Feretima a causa de su crueldad con la de Herodes el Grande, descrita por Josefo, Ant. XVII, 6, 5 y en los Hechos de los Apóstoles XII, 23.

${ }_{62}$ Se trata, por supuesto, de un relato de carácter etiológico, muy del gusto de nuestro autor. Véase J. Carlier-Détienne, "Les amazones font la guerre et l'amour", L'Ethnographie, 76, 1980-1981, pp. 13 y 18; W.B. Tyrrell, Amazons. A Study in Athenian Mythmaking, Baltimore, 1984, p. 41; J.H. Blok, The Early Amazons. Modern and Ancient Perspectives on a Persistent Myth, Leiden, 1995, pp. 86-89. Sobre las imágenes de amazonas representadas como tracias o escitas en el arte griego, H.A. Shapiro, "Amazons, Thracians and Scythians", GRBS, 24, 1983, pp. 105-114.

EMERITA (EM) LXXV 2, julio-diciembre 2007 pp. 299-317 ISSN 0013-6662 
enfrentó a Heracles con Hipólita ${ }^{63}$, la reina de las amazonas, en una batalla librada junto al río Termodonte ${ }^{64}$. Tras obtener la victoria, los griegos se hicieron a la mar llevándose prisioneras a numerosas amazonas. Sin embargo, en alta mar, las mujeres se rebelaron contra sus captores -hombres, por supuesto- y los arrojaron por la borda; a pesar de ello, no sabían pilotar las barcos -eran bárbaras, por tanto, desconocían los adelantos técnicos- y no tuvieron más remedio que dejarse llevar por el viento y las olas hasta arribar a Cremnos, en la costa del mar de Azov.

La actividad desarrollada por las amazonas después de desembarcar consistió en saquear las posesiones de los escitas ${ }^{65}$.

Éstos quedaron extrañados ante el comportamiento y la apariencia de sus agresores, a quienes tomaron por adolescentes, ya que no tenían barba. Únicamente comprendieron que eran mujeres cuando lucharon contra ellas y observaron a las que habían caído en combate.

A partir de ese momento, la estrategia seguida por los escitas no pudo ser más novelesca ${ }^{66}$, ya que decidieron enviar a sus soldados más jóvenes cerca del campamento de las amazonas al objeto de seducirlas y engendrar hijos con ellas, posiblemente en espera de que éstos se convirtieran en grandes guerreros ${ }^{67}$.

Ambas comunidades, que tenían un número similar de miembros, se encontraban cada vez más cercanas, hasta que un día un escita se abalanzó sobre una amazona que se encontraba sola y ésta no lo rechazó. Como no hablaban el mismo idioma, la mujer le indicó por gestos que al día siguiente

\footnotetext{
${ }^{63}$ No obstante, Heródoto no mencionó sus nombres, ni el de Teseo, quien, según el mito, había participado en este trabajo de Heracles, porque poco después afirmó que las amazonas prisioneras se liberaron y mataron a quienes las habían vencido. Evidentemente, Heródoto no podía permitir que Heracles y, menos aún, Teseo -un héroe estrechamente vinculado a Atenas, la ciudad que venció a las amazonas- fuesen derrotados en esta versión de los hechos.

${ }^{64}$ Situado en Capadocia, junto al cual se localizaban legendariamente las amazonas. Todo este episodio se contiene en Hdt. IV, 110-117.

${ }_{65}$ Debemos suponer que se trataría fundamentalmente de sus rebaños.

66 O, según C. Dewald, "Women and culture", p. 100, "estructurada como una comedia" en la que ambos sexos aprenden a vivir en común partiendo de una situación de origen absolu-

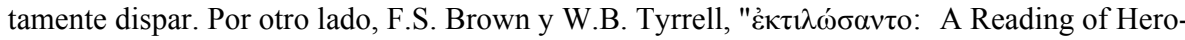
dotus' Amazons", CJ, 80, 1985, pp. 297-302, ofrecieron una interpretación antropológica en clave de "ritos de pasaje", lo cual no era seguramente lo más adecuado para explicar todo el relato.

67 J. Carlier-Détienne, "Les amazones", p. 20.
} 
acudiese al mismo lugar y que llevase a un compañero, dándole a entender que ella traería a otra amazona.

Al final, todos acabaron emparejados, incluso llegaron a unir ambos campamentos y las amazonas terminaron hablando la lengua escítica ${ }^{68}$. Lo primero que les dijeron los escitas es que ellos tenían padres y propiedades como símbolos de su "civilización", en contraposición a las amazonas, que no conocían a sus padres y tampoco tenían propiedades estables- y no estaban dispuestos a continuar el género de vida que llevaban -es decir, la caza y el pillaje, actividades propias de las míticas amazonas-, de modo que les propusieron residir entre los suyos convirtiéndolas en sus esposas.

Las amazonas, fieles a su naturaleza "bárbara" y antisocial, les respondieron que ellas eran incapaces de convivir con las mujeres escitas puesto que no tenían las mismas costumbres. A continuación, enumeraron las propias de las amazonas: manejar el arco, lanzar venablos y montar a caballo. En cambio, las escitas realizaban las tareas consideradas propias de mujeres dentro de sus carros, debido a que el pueblo escita, por lo general, llevaba una vida nómada y carecía de casas.

Las amazonas lograron convencer a los jóvenes para que regresaran junto a sus padres, tomasen la parte de sus bienes que les correspondía y regresasen junto a ellas para vivir por su cuenta ${ }^{69}$.

Finalmente, los escitas las obedecieron y acabaron instalándose al este del río Tanais dando origen a la etnia saurómata ${ }^{70}$, que hablaba la lengua escítica con algunas particularidades locales ${ }^{71}$. Las mujeres saurómatas de la época

\footnotetext{
68 El comentario al respecto de W.W. How y J. Wells, A Commentary on Herodotus I, Oxford, $1975^{8}$, p. 341, resulta políticamente incorrecto.

69 Como señalaron J. Carlier-Détienne, "Les amazones", p. 20 y, en especial, W.B. Tyrrell, Amazons, pp. 41-43, 77, en este pasaje se aprecia una inversión de las normas patriarcales griegas: los escitas de este relato, al igual que ocurría con las mujeres griegas, contraen matrimonio muy jóvenes; ellos aportan aquí la dote; en Grecia, eran las mujeres quienes se dirigían al domicilio de su esposo, mientras que en la presente historia las amazonas eligen el sitio donde van a asentarse con los escitas para que ellas precisamente sigan llevando a la práctica sus peculiares costumbres. En un sentido similar se manifestaron M. Rosellini y S. Saïd, "Usages de femmes", pp. 998-1003.

70 T. David, "La position de la femme en Asie Centrale", DHA, 2, 1976, pp. 146-154, trató acerca de las costumbres y modo de vida de los saurómatas, entre otros pueblos del Asia central mencionados en la obra de Heródoto.

${ }^{71}$ Este rasgo etnográfico parece ser cierto; sería, por tanto, un reflejo de la situación existente en el siglo V a.C.
} 
de Heródoto mantenían muchas costumbres de las amazonas: salían a cazar a caballo e iban a la guerra con el mismo atuendo que los hombres.

Como pervivencia de un rasgo cruel, mencionó el autor una norma que regía entre los saurómatas: para contraer matrimonio, toda doncella tenía que matar previamente a un enemigo ${ }^{72} \mathrm{y}$, para dar a entender la veracidad de esta costumbre, señaló que algunas mujeres fallecían ancianas y solteras por no haber podido cumplir esta norma.

El último ejemplo de crueldad femenina que vamos a tratar en el presente trabajo se refiere a una venganza cometida de manera solidaria por las mujeres atenienses sobre la persona del único superviviente de la expedición enviada por Atenas contra Egina para recuperar las estatuas de dos divinidades realizadas en madera de olivo procedente del Ática ${ }^{73}$.

Según Heródoto, tanto la versión ofrecida por los argivos y eginetas como la de los propios atenienses coincidían en señalar que sólo un hombre pudo regresar con vida a Atenas.

Tal individuo informó del desenlace de la operación y, al saber lo ocurrido, las esposas de los fallecidos, indignadas por el hecho de que ese hombre hubiese sobrevivido, se arrancaron las fíbulas de los vestidos y se las clavaron hasta matarlo, llevando a cabo, de esa manera, una contrapartida "femenina" al bien atestiguado rito de la lapidación, practicado por ciudadanos fuera del recinto urbano frente a alguien que ha puesto en peligro la paz social y la convivencia dentro de la ciudad ${ }^{74}$.

Ante semejante acción, los atenienses decidieron que, a partir de enton-

72 Una noticia similar fue recogida por Nicolás de Damasco en F.Gr.Hist. 90 F 103 f); en el tratado hipocrático De aeribus aquis locis 17, las mujeres saurómatas debían acabar con la vida de tres hombres. Por su parte, Tac., Germ. 31, mencionó asimismo un "rito de paso" similar entre los guerreros germánicos.

73 Hdt. V, 85-87. Según A. Andrewes, "Athens and Aegina, 510-480 B.C.", ABSA, 37, 1936-1937, pp. 1-7 y otros autores de las primeras décadas del siglo XX, tal expedición se produjo hacia los años 489 ó 488 a.C. En cambio, L.H. Jeffery, "The campaign between Athens and Aegina in the years befote Salamis (Herodotus, VI, 87-93)", AJPh, 83, 1962, pp. 44-54, opinó que fue previa a la batalla de Maratón, teniendo lugar en 491 o durante los primeros meses de 490 a.C.

${ }_{74}$ M. Gras, "Cité grecque et lapidation", en Du châtiment dans la cité. Supplices corporels et peine de mort dans le monde antique, Roma, 1984, pp. 75-88, expuso varios ejemplos de lapidaciones o castigos similares (como éste que aquí nos ocupa) efectuados sobre los mensajeros que llevaban malas noticias, quienes jugaban, de esa manera, un papel semejante al de los pharmakoi jonios. 
ces, las mujeres atenienses tendrían que usar el vestido jónico en lugar del dórico, que iba precisamente abrochado con fíbulas ${ }^{75}$.

No se trata ésta de la única mención realizada por Heródoto al asesinato de algún hombre por parte de un grupo de mujeres. Las habitantes de Lemnos asesinaron a sus respectivos esposos en tiempos del rey Toante ${ }^{76} \mathrm{y}$ también sabemos acerca del linchamiento de los familiares del buleuta Lícidas a manos, nuevamente, de las atenienses ${ }^{77}$.

\section{Conclusión}

De entre todo el material literario que acabamos de examinar, se desprende la idea de que Heródoto confirió en un mayor número de ocasiones una personalidad cruel y vengativa a las mujeres pertenecientes a las distintas casas reales orientales o, en todo caso, a algunas mujeres de origen griego dotadas de poder político pero que lo ejercían en los límites del mundo helénico, no en el seno de una polis. El caso de las iracundas mujeres atenienses constituiría una excepción a esta regla general, puesto que el superviviente regresado de Egina fue víctima de una violencia desbocada e irracional, en definitiva, de un acto puntual.

Por supuesto, Heródoto encontró en las poderosas féminas orientales unos personajes idóneos para ejercitar la ỏ $\rho \eta ́$. En las poleis griegas - excepto en las mencionadas zonas periféricas - la monarquía había sido abolida hacía mucho tiempo y la mentalidad social predominante no resultaba excesivamente dispuesta a aceptar la idea de que las mujeres ejerciesen el poder político.

75 Cuando, en realidad, parece que el cambio de una prenda a otra fue gradual durante la segunda mitad del siglo VI a.C., cuando creció de manera considerable la renta disponible por los atenienses y éstos pudieron acceder a prendas de vestir más costosas como el quitón de lino

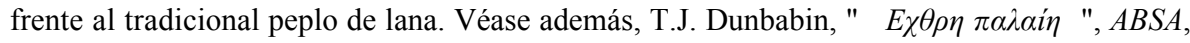
1936-1937, pp. 85-86.

${ }^{76}$ Hdt. VI, 138. Aquí, el autor, se refirió brevemente a este mito, según el cual las mujeres de Lemnos fueron castigadas por Afrodita, quien hizo que sus cuerpos despidiesen un olor desagradable provocando el correspondiente rechazo de sus maridos, los cuales prefirieron tener relaciones con las esclavas. En venganza, las lemnias los asesinaron a todos excepto a Toante.

77 En Hdt. IX, 5. M. Gras, "Cité grecque et lapidation", p. 86, señaló que, en las fuentes literarias griegas, la acción espontánea, apasionada e histérica era propia de las mujeres; en cambio, la lapidación llevada a cabo ritualmente por los ciudadanos se trataba de un acto responsable en beneficio de la propia comunidad. 
A esto debemos añadir un elemento propio del pensamiento herodoteo: en las monarquías orientales, el poder absoluto del soberano no conocía ningún tipo de cortapisa, de modo que aquél podía adoptar todas las medidas que considerase necesarias sin tener en cuenta los inexistentes derechos de su súbditos, en contraposición a lo que ocurría en el ordenado y "democrático" mundo griego. Por tanto, los déspotas orientales - e incluso todavía peor, sus esposas e hijas, más predispuestas a una venganza desaforada debido a su naturaleza femenina, según mantenía la mentalidad predominante en Grecia - se veían libres de mostrar su verdadera personalidad, que en no pocas ocasiones conllevaba una actuación sumamente injusta y violenta.

Con respecto a esta última apreciación, no queremos ofrecer una lectura simplista de Heródoto, basada en "los buenos griegos" y "los malos bárbaros", que en ningún momento pensamos que exista en la Historia ${ }^{78}$. Nuestro autor era lo suficientemente sutil e inteligente como para no presentar un relato en blanco y negro; más bien, lo que nosotros entendemos que quiso transmitir fue la idea de que el poder sin el debido control, independientemente de quien lo ejerciese, podría dar lugar en muchas ocasiones - prácticamente en todas - a unos comportamientos tan arbitrarios cuyas consecuencias, sin duda, horrorizaron a los griegos contemporáneos de Heródoto.

Con arreglo a las normas editoriales vigentes para las publicaciones periódicas del CSIC, se hace constar que el original de este artículo se recibió en la redacción de EMERITA en el segundo semestre de 2006, siendo aprobada su publicación en el primero de 2007 (01.11.06 - 14.01.07)

78 Basta recordar la equilibrada imagen que ofreció sobre los persas en general, poniendo de manifiesto, eso sí, el desequilibrio y la crueldad de determinados personajes, como Cambises, Jerjes y algunos otros miembros de la familia real.

EMERITA (EM) LXXV 2, julio-diciembre 2007 pp. 299-317 ISSN 0013-6662 